\title{
Not a make-up, but an alarm signal of a new onset of Addison's disease
}

\author{
Roxana Stanciu*, Piotr Brzezinski**, Liliana Foia****, Claudia Miron^${ }^{*}$, Anca Chiriac $^{\wedge \wedge}$ \\ *Nicolina Medical Center, Endocrinology, Iasi-Romania, ** Department of Dermatology,6th Military Support Unit, Ustka, Poland \\ *** University of Medicine and Pharmacy" Gr T Popa" Iasi, Romania, ^Endocrinology CMI,Iasi-Romania, \\ $\wedge \wedge$ University Apollonia, Nicolina Medical Center, Department of Dermatology,Iasi-Romania
}

Case report: A 52 year old woman had an appointment at the Dermatology Department for a previous diagnosis of melasma. She was seen in October and her pigmentation had appeared somewhere during summer. She did not recall any drug intake, she denied sun exposure in the recent past, and she was a social employee working indoor.

At the clinical examination intense hyperpigmentation around the eyes was noted, In contrast with the rest of the skin of normal aspect. The pigmentation was very well demarcated with no symptoms associated.

Our first gesture was to ask the lady to use a cotton swab to clear the make-up, obviously with no results. Local trauma and melasma were excluded from the beginning.

A minutious clinical examination was performed, but remained unremarkable; no history of fatigue or anxiety, no sleep disturbance, no loose of appetite or weight loss, no complaints. Blood pressure and pulse were normal.

Routine laboratory investigations were within normal range including fasting blood, serum urea, creatinine and electrolyte; anti-HIV, anti hepatitis $\mathrm{C}$ virus hepatitis $\mathrm{B}$ surface antigen ( $\mathrm{HCV}, \mathrm{HBs} \mathrm{Ag})$ factors were negative.

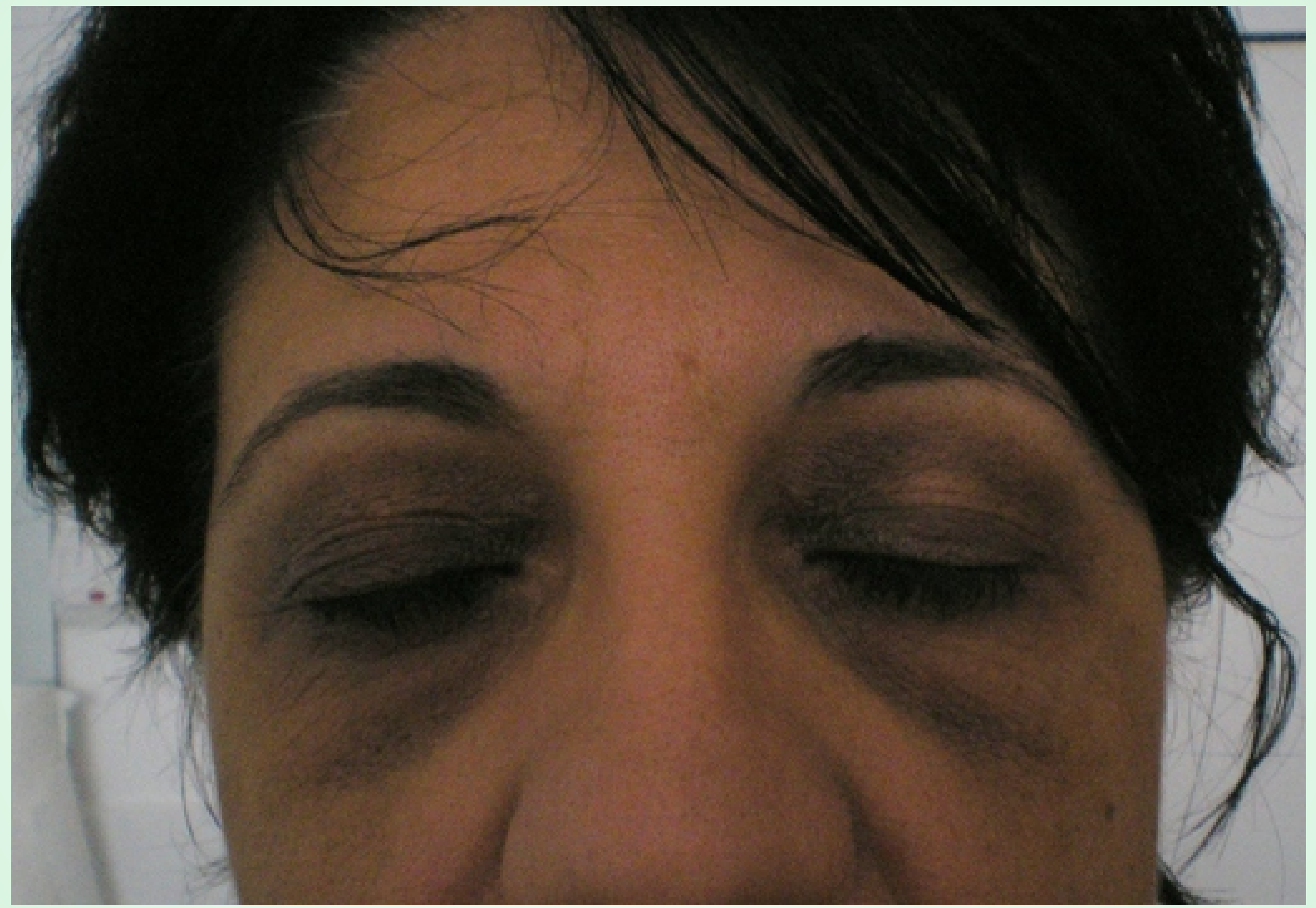

Due to a suspicion of Addison's disease an early morning cortisol level was asked and turned to be below normal value. A diagnosis of Addison's disease was supported and the patient was sent to the Endocrinology Department for further investigations and close monitoring of the disease.

\section{Discussion}

Although described in 1885 by Thomas Addison is still a rare disorder, being reported with a frequency of 1 in 100.000 people. [1]

The evolution of the disease is silent and long, over months-years, until it is recognized, sometimes in crisis. The classical clinical picture of Addison's disease is apparent when 90\% of the glandular tissue has been destroyed.[2]

As dermatologists it is important to be able to recognize and suspect Addison's disease in front of typical skin lesions: cutaneous and mucosal hyperpigmentations, thin and brittle nail, scanty body hair[3]. Pigmentation can be homogenous or mottled, may be present on the skin, but also oral cavity, conjunctiva and genitalia. Specific pigmentation of gingival, vermillion border of the lips, buccal mucosa, palate, and tongue may raise the suspicion of Addison's disease even in the absence of other clinical signs.[4]

The present case stresses the importance of an early diagnosis of Addison's disease in the context of a peculiar hyperpigmentation in the absence of other signs and symptoms.

\section{References}

1. Grossman AB.Thomas Addison and his disease.Grand Rounds. 2004; 4: L8-9

2. Sarkar SB, Sarkar S, Ghosh S, Bandyopadhyay S. Addison's disease.Contemp Clin Dent.2012 Oct;3(4):484-6.

3. O'Connell S, Siafarikas AAddison disease - diagnosis and initial management. Aust Fam Physician.2010 Nov; 39(11):834-7.

4. Lanza A, Heulfe I, Perillo L, Dell'Ermo A, Cirillo N. Oral manifestation as a sign of Addison's disease: A brief reappraisal. Open DermatolJ.2009;3:3-6. 